\title{
Methodological issues in the study of e- government in the Republic of Bulgaria
}

\author{
Katia Kirilova ${ }^{1 *}$ \\ ${ }^{1}$ University of National and World Economy - Sofia, Bulgaria
}

\begin{abstract}
The digital transformation of processes and services is a priority for the Bulgarian society and economy. This is especially true in the context of a global pandemic. Online work and training require state and municipal administration to provide additional efforts for digitalization. In this context, the main methodological issues in the study of the e-government system in the Republic of Bulgaria will be presented. The applied methods are related to: analysis and evaluation of the applicable regulatory framework; analysis of the possible technological solutions for conducting surveys among the municipal administration; methods related to the possibilities for statistical analysis of the obtained results. The main results are in the direction of clarifying the applicable methodological and technological tools for studying the degree of development of the e-government system. The conclusions are in the direction of the achieved methodological and technological readiness for conducting a survey in the local administration.
\end{abstract}

\section{Introduction}

The problems of the development of e-government and digital administrative services are becoming more and more topical. The Covid-19 crisis has significantly accelerated the process of using electronic communication channels. The normative base and the strategic documents describe the main approaches for realization of the processes for providing services for the citizens and the business. The Law on Electronic Government [1] defines the legal interrelations and administrative processes and services. It also describes the possible interactions of users with persons performing public functions. The law provides for these interactions to take place using information and communication technologies. The updated strategy for development of e-government in the Republic of Bulgaria (2019-2025) presents the forms of interaction between the participants in e-government. The models of interaction between the participants in the e-government are [2]:

- "Administration - Citizen";

- "Administration - Business";

- "Administration - Administration";

- EU Member State - EU Member State.

* Corresponding author: katia.kirilova@unwe.bg 
The defined interaction models are the basis for constant analysis of the technological and process relationships between the participants. Other important normative documents in this subject area are Regulation (EU) № 910/2014 [3], Electronic Identification Act [4], Electronic Document and Electronic Certification Services Act [5], National Strategic Document "Digital Transformation of Bulgaria for period 2020-2030" [6] and others. These documents set out the basic principles for building information systems and the provision of digital administrative services. The current legal framework is the basis on which central and local administrations develop their information models. This provides a very wide range of opportunities for empirical research and studies.

\section{Research methodology}

The study of the e-government system in the Republic of Bulgaria is a complex task. On the one hand, this process is associated with a careful analysis of the public resources allocated over the years for digitalization. On the other hand, it is necessary to monitor the attitudes of citizens and businesses, the general economic situation, and economic results.

There are many methods that can be applied to study e-government in a country. Each of these methods is accompanied by certain data sources, which are the basis for the analyzes. The growing role of semi-structured and unstructured data as a source of data for the study of digital services in the respective country is increasingly researched [8].

In accordance with the defined purpose of the study Fig. 1 presents the main applicable methods and the relevant data sources for the present study.

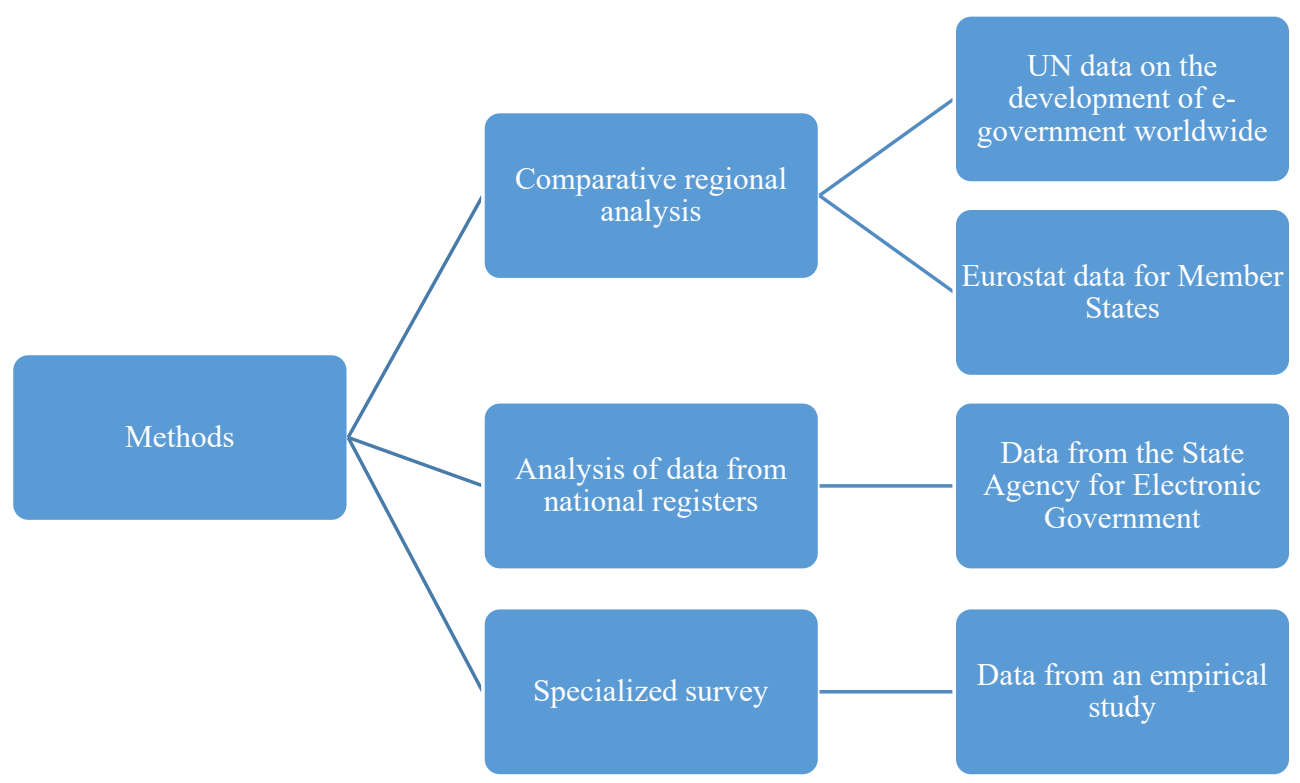

Fig. 1. Applicable research methods

The present study uses three main methods, namely: the comparative regional analysis, the analysis of data from national registers and the specialized survey. As described, they include four main data sources, namely:

- UN data on e-government development worldwide;

- Eurostat data for Member States; 
- data from the State Agency for Electronic Government;

- data from an empirical study.

In the present study, the focus will be on the third method described. Conducting a survey requires significant preliminary preparation actions (Fig. 2):

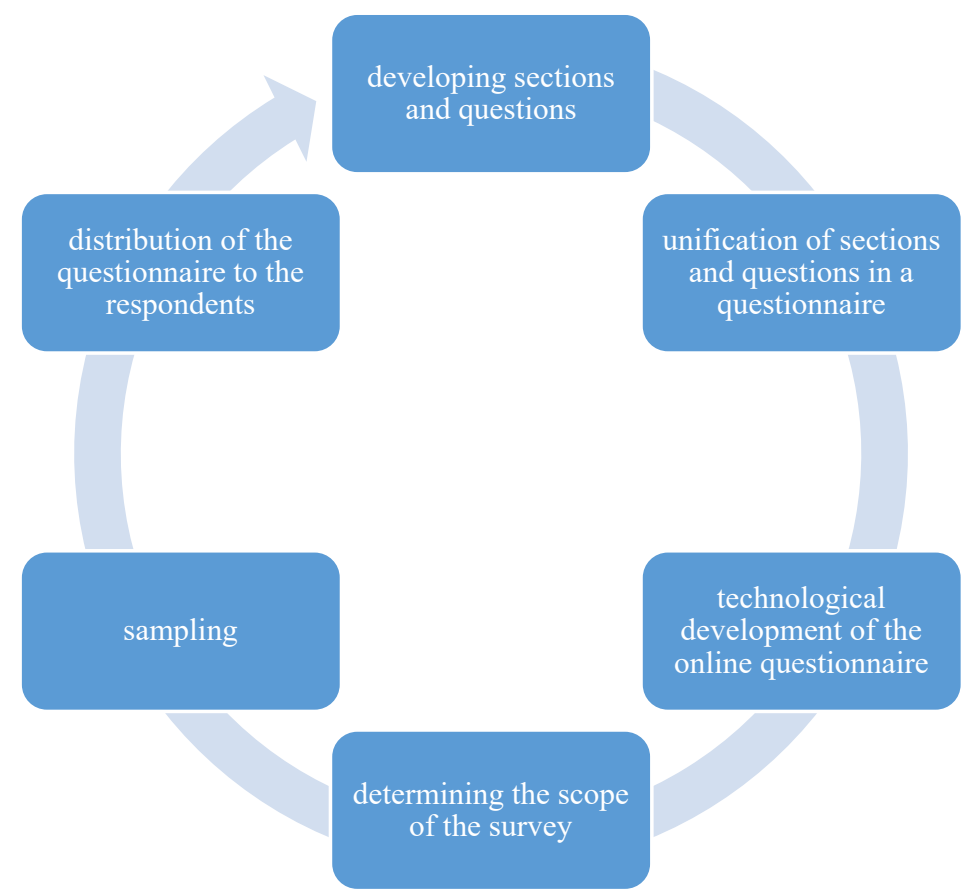

Fig. 2. Survey process

These stages include:

- developing sections and questions;

- unification of sections and questions in a questionnaire;

- technological development of the online questionnaire;

- determining the scope of the survey;

- sampling;

- distribution of the questionnaire to the respondents.

An essential element of the e-government system is the provided digital administrative services. They are provided both by the state administration bodies and by the local administration bodies. The provision of such services also requires the availability of relevant digital competencies. They should be validated in the process of career development of the employees of the administration [7]. In essence, the municipalities in the Republic of Bulgaria are one of the main providers of digital administrative services for citizens and businesses. For these reasons, for the purposes of this study, the developed questionnaire aims to conduct a survey in the local administration. In this way, the following three main sections in the composition of the questionnaire are formed (Fig. 3):

- digitalization policy;

- electronic management in the municipality;

- digital administrative services. 


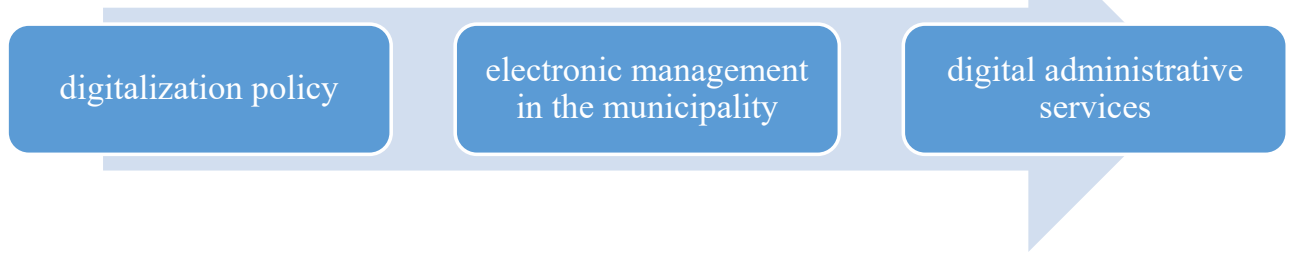

Fig. 3. Sections in the questionnaire

The first section on "digitalization policy" includes the following main issues:

- Does the municipality have developed and implemented its own policy in the field of digitalization?

- How many years have you been developing digitalization of processes and / or services?

- How many experts from the municipality participate in the digitalization processes?

- Do you think that the digitalization of processes and / or services will be more successful for you if it is outsourced to an external IT company?

- What are the main challenges to digitalization in the municipality?

The second section "electronic management in the municipality" includes the following main issues:

- What percentage of the registers maintained in the municipality are in digital format, which is suitable for data exchange?

- What percentage of users of administrative services use the secure electronic service system?

- How many electronic identification methods does the municipality provide?

- Does the municipality conduct a cybersecurity risk analysis?

- Has the municipality developed its own mobile applications?

The third section "digital administrative services" includes the following main issues:

- How many new digital services do you develop and implement in the municipality (average per year)?

- How many users in the municipality use digital administrative services (average per year)?

- What percentage of administrative services are digitized?

- What percentage of the offered digital administrative services are at the level of twoway communication without the possibility for electronic delivery and electronic payment?

- What percentage of the offered digital administrative services are at the level of twoway communication with the possibility of electronic delivery and electronic payment?

Based on the developed sections and questions in the research a technological realization of an online questionnaire is proposed.

\section{Results}

The main results of this part of the research are related to the technological implementation of the questionnaire for the study of e-government and digital administrative services in the Republic of Bulgaria [9]. In Fig. 4 and Fig. 5 is given the graphical presentation of the developed questionnaire. 


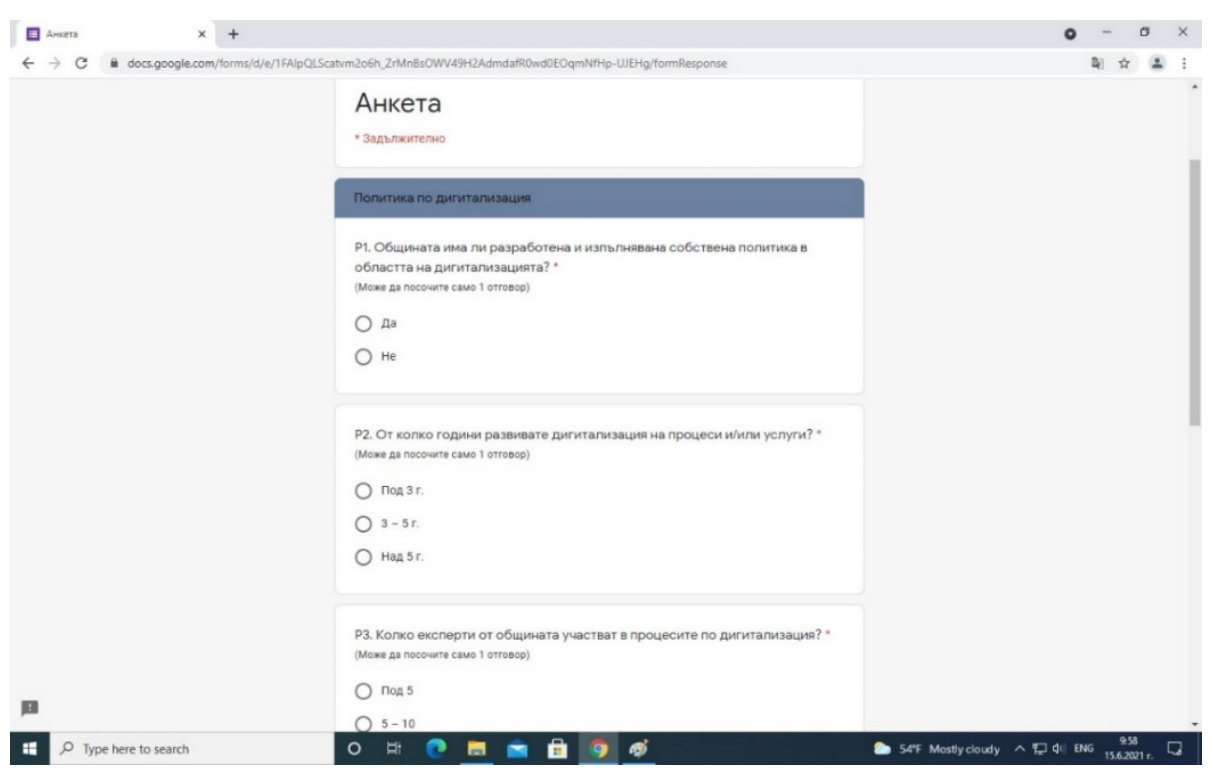

Fig. 4. Screen from the developed questionnaire - part 1

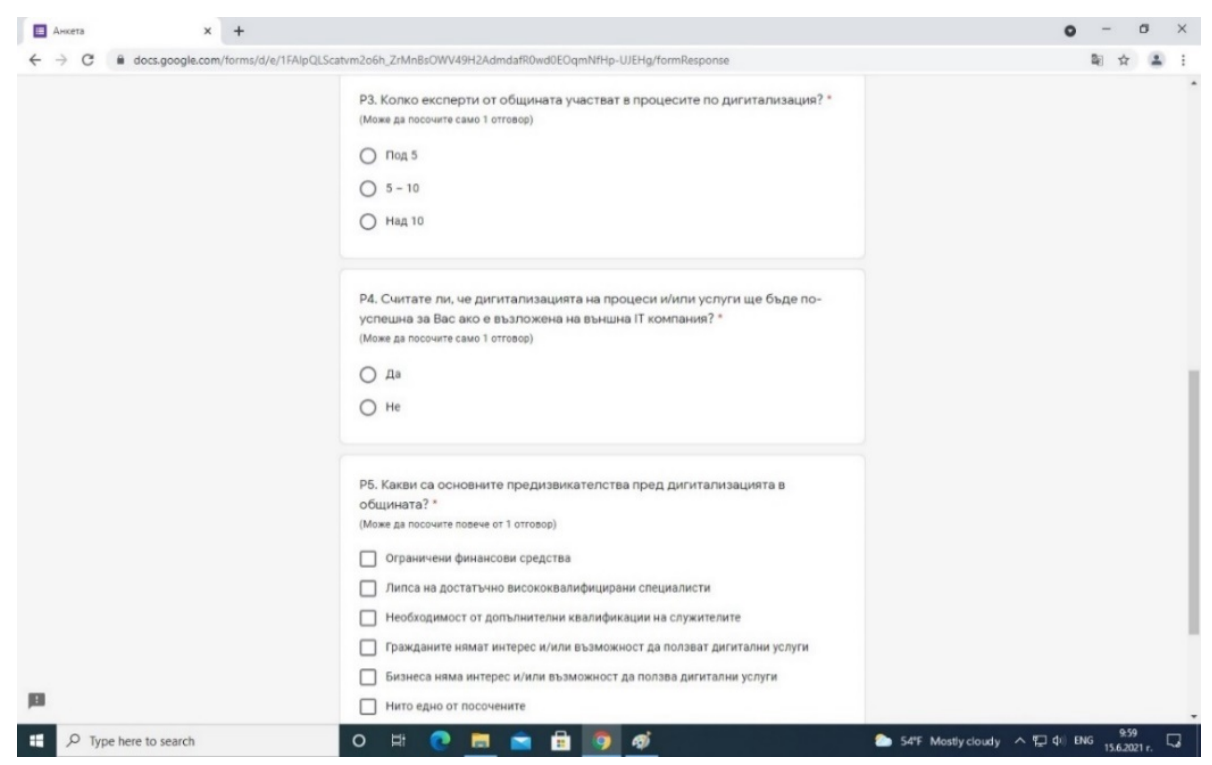

Fig. 5. Screen from the developed questionnaire - part 2

The questionnaire is structured in the relevant sections. The questions asked aim to assist the respondents in submitting the answers. For these reasons, there are several types of questions in the questionnaire:

- with one possible answer;

- with more than one possible answer;

- to fill in numeric values.

The scope of the survey includes all municipalities in the Republic of Bulgaria. For the purposes of the empirical study, a sample was determined, which includes 45 municipalities or about $18 \%$ of the general population. The formation of such a sample creates conditions 
for representativeness of the study and correct interpretation of the results. The link to the questionnaire is distributed electronically to the e-mail addresses of the respondents. They also fill in the proposed questionnaire via the internet form for it.

\section{Conclusions}

As a result of the developed methodological and technological part the following main conclusions can be formulated:

- the collection of empirical data on the state of e-government and digital administrative services requires the development of methodological tools;

- the application of empirical research methodologies also includes the determination of relevant stages of the activities;

- the conduct of empirical research should be carried out through representative samples;

- The experience gained in online surveys allows the collection of reliable data to allow appropriate analysis and recommendations.

This work was supported by the UNWE Research Programme (Research Grant No. NID NI-7/2020).

\section{References}

1. Electronic Government Act (2020), https://e-gov.bg/wps/portal/agency/aboutus/ordinances-laws, [Accessed: 21 June 2021]

2. The updated strategy for development of e-government in the Republic of Bulgaria 2019-2025, (2021), https://e-gov.bg/wps/portal/agency/strategies-policies/emanagement/strategic-documents, [Accessed: 21 June 2021]

3. Regulation (EU) 910/2014 (2014), https://eur-lex.europa.eu/legalcontent/EN/TXT/PDF/?uri=CELEX:32014R0910, [Accessed: 21 June 2021]

4. Electronic Identification Act (2021), https://www.mtitc.government.bg/bg/legal_acts, [Accessed: 21 June 2021]

5. Electronic Document and Electronic Certification Services Act (2021), https://www.mtitc.government.bg/bg/legal_acts, [Accessed: 21 June 2021]

6. National strategic document: Digital Transformation of Bulgaria for the period 20202030 (2020), https://www.mtitc.government.bg/, [Accessed: 21 June 2021]

7. R. Kirilov, Econ. Altern. J., 1, 184-195 (2020)

8. P. Milev, Economic and Social Alternatives, 2, 58-69 (2018)

9. Questionnaire (2021), https://docs.google.com/forms/d/e/1FAIpQLScatvm2o6h_ZrMnBsOWV49H2Admdaf

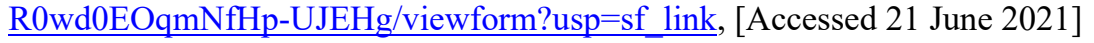

